\title{
Satisfaction and associated factors of outpatient psychiatric service consumers in Ethiopia
}

\author{
This article was published in the following Dove Press journal: \\ Patient Preference and Adherence \\ 19 September 2016 \\ Number of times this article has been viewed
}

\section{Solomon Yimer' \\ Zegeye Yohannis ${ }^{2}$ \\ Wondale Getinet ${ }^{3}$ \\ Tesfa Mekonen ${ }^{4}$ \\ Wubalem Fekadu ${ }^{4}$ \\ Habte Belete ${ }^{4}$ \\ Melak Menberu ${ }^{5}$ \\ Asmamaw Getnet ${ }^{6}$ \\ Amsalu Belete ${ }^{7}$}

'Psychiatry Department, College of Health Sciences and Medicine, Dilla University, Dilla, ${ }^{2}$ Amanuel Mental Specialized Hospital, Addis Ababa, ${ }^{3}$ Psychiatry Department, College of Health Science and Medicine, University of Gondar, Gondar, ${ }^{4}$ Psychiatry Department, College of Medicine and Health Sciences, Bahir Dar University, Bahir Dar, ${ }^{5}$ Department of Nursing, College of Health Sciences, Mizan-Tepi University, Mizan, ${ }^{6}$ Finote Selam Hospital, Finote Selam, ${ }^{7}$ Department of Nursing, College of Health Sciences and Medicine, Debre Tabor University, Debre Tabor, Ethiopia
Correspondence: Tesfa Mekonen Psychiatry Department, College of Medicine and Health Sciences, Bahir Dar University, Bahir Dar,

PO Box 79, Ethiopia

Tel +25 I 9 I264 04I2

Fax +25I 582205932

Email smarthopel@gmail.com
Purpose: The purpose of this study was to assess the level of patient satisfaction and associated factors with psychiatric outpatient services in Ethiopia.

Patients and methods: A cross-sectional study was performed from May 2015 to June 2015. A total of 454 participants selected by systematic random sampling were included in this study. Pretested and interviewer-administered questionnaire was used to collect the data. Patient satisfaction was measured using Charleston Psychiatric Outpatient Satisfaction Scale, and other validated tools were used to assess the associated variables. Multivariate logistic regressions with $95 \%$ confidence interval (CI) were used to assess the strength, and $P$-value $<0.05$ was used to indicate significance of association.

Results: A total of 441 respondents were enrolled, with a response rate of $97.1 \%$ and magnitude of satisfaction of $61.2 \%$. Being male (adjusted odds ratio [AOR] $=0.612,95 \% \mathrm{CI}: 0.39,0.94$ ), being widowed $(\mathrm{AOR}=0.13,95 \% \mathrm{CI}: 0.05,0.36)$, urban residence $(\mathrm{AOR}=0.49,95 \% \mathrm{CI}: 0.31$, $0.78)$, diagnosed with schizophrenia ( $\mathrm{AOR}=0.48,95 \% \mathrm{CI}: 0.28,0.81)$, unfavorable attitude (AOR $=0.49,95 \% \mathrm{CI}: 0.28,0.86)$, and poor social functioning (AOR $=0.52,95 \% \mathrm{CI}: 0.34,0.80)$ were significantly associated with satisfaction.

Conclusion: More than one-third of psychiatric service consumers were dissatisfied with the service they received. Integrating patients to their own treatment plan and regular service evaluation are important to improve satisfaction.

Keywords: patient satisfaction, mental illness, social functioning

\section{Introduction}

Satisfaction is a general psychological condition that results from emotional surrounding expectations coupled with the prior feeling of consumers toward the consumption experience. ${ }^{1}$ Even though it is difficult to find an agreed-upon definition, patient satisfaction is "health care recipient's reaction to salient aspects of his or her experience, expectation and preference of a service" met by health care service and provider. $^{2}$ Patient satisfaction is one desired outcome of mental health care service and core parameter for the positive evaluation of a mental health care system. ${ }^{3-5}$ For consumers of mental health services, satisfaction has become a significant contributing outcome in the assessment and improvement of quality of care, including adherence to treatment, intent to return for care and follow-up, and continuity of outpatient care. ${ }^{6}$

Different studies showed that the global level of patient satisfaction to psychiatric services ranges from $39.3 \%$ to $91.9 \%$, with $39.3 \%$ in London, ${ }^{7} 44.8 \%$ in the university hospitals of Canada and USA, ${ }^{8} 57 \%$ in India, ${ }^{9} 90 \%$ in Ireland, ${ }^{10}$ and $91.9 \%$ in South Africa. ${ }^{11}$ A range of factors can affect patient satisfaction, including unpleasantly built environments, staff being too busy, failure to obtain prescribed medications from the hospital pharmacies, the stigma of a psychiatric treatment service, long waiting hours, 
form of treatment and quality of care, treatment process and results, and payment for psychiatric services. Consequently, a dissatisfied patient is not psychologically and socially well becoming evident of lack of goal attainment by the service provider or the clinician. ${ }^{12-14}$ Different studies also indicated that, other than the quality of service delivery, satisfaction is also affected by many factors such as patients' demographics, ${ }^{15,16}$ diagnosis and duration of disease, ${ }^{17,18}$ treatment program, ${ }^{19}$ and patients' expectation of service. ${ }^{20}$

It is indicated that health care systems in most developing countries suffer from serious deficiencies in financing and efficiency and are poorly prepared to meet the challenges related to patient satisfaction. ${ }^{21}$ Satisfied patients are likely to exhibit favorable behavioral intentions, which are important for long-term success of the health care providers and are more likely to complete treatment regimens and be compliant and cooperative. ${ }^{22}$

Reliance on psychiatric symptoms alone as a measure of service satisfaction is somehow a narrow concept; it is rather important to see how satisfied the patients are by the service they received. ${ }^{23}$ Patient satisfaction is one of the yardsticks to measure the success of mental health service. Despite psychiatric outpatient service being given in most of referral hospitals in Ethiopia, there had been lack of evidence that examined patients' satisfaction with the quality of psychiatric care based on sound theoretical frameworks, and this study was probably the first to assess satisfaction of psychiatric patients in this area. Therefore, it is imperative to consistently undertake surveys in the community or facility to introduce better services that fulfill patients' expectations. ${ }^{24}$ Hence, the aim of this study was to determine the level of patient satisfaction and associated factors of psychiatric service consumers.

\section{Patients and methods}

A cross-sectional study was conducted from April 2015 to May 2015 to assess the level of patient satisfaction and associated factors of psychiatric service consumers at Dessie Referral Hospital, which is located in Dessie town, $401 \mathrm{~km}$ northeast of Addis Ababa. During the study, Dessie town had a total population of 279,423 with ten urban sub cities, one referral hospital, three private hospitals, and four governmental health centers. The hospital is a regional referral hospital that was established in 1962 and serves people of North and South Wollo zones and people of the neighboring Afar areas. The hospital initiated outpatient psychiatric service in 1989 and currently serves $\sim 15,000$ psychiatric patients every year. Ethical clearance was obtained from University of Gondar and Amanuel Mental Specialized Hospital Institutional Review Board (IRB). Participants had the right to refuse the interview and to discontinue at any time they want. Confidentiality was maintained by anonymous questionnaire and informed consent was obtained from each participant.

All adult psychiatric patients aged 18 years and older who received treatment for at least 6 months from the outpatient department were included in this study and those who were not able to communicate due to serious illness were excluded. The sample size was estimated by Epi Info (CDC, Atlanta, Georgia, USA) with 95\% confidence interval (CI), 80\% power, 2 odds ratio, $11.1 \%$ proportion, and $10 \%$ nonresponse rate, which yielded the final sample of 454 . The proportion used in the sample size calculation was based on the presurvey pilot result, which was done for the purpose of pretesting the questionnaire, and the level of preliminary dissatisfaction for those who resided in the rural area was $11.1 \%$. Systematic random sampling technique was used to recruit the participants. The randomization was made systematically in every other patients during the data collection period, and the first participant was selected randomly by the lottery method.

Patients' level of satisfaction was the outcome variable, and the independent variables were age, sex, religion, marital status, ethnicity, employment, education, economical status and residence, type of psychiatric diagnosis, duration of illness, number of medications and comorbid medical illnesses, patient's attitude toward service, and social functioning.

Data were collected by interviewing participants and reviewing patients' charts using semistructured and pretested questionnaires. Patient satisfaction was assessed by Charleston Psychiatric Outpatient Satisfaction Scale, a 15-item Likert scale ranging from 1 to 5, where 1 indicated "poor" and 5 "excellent". The scale was scored by summing each item, and satisfaction was considered to be high if the participant scored average and above of the scale. ${ }^{25,26}$ Charleston Psychiatric Outpatient Satisfaction Scale was validated in Nigeria and showed good validity and readability to be used in low- and middle-income countries. ${ }^{27}$ Patients' psychosocial functioning was measured using Social Functioning Questionnaire (SFQ), an eight-item scale that was used to measure general social functioning in a study done at the University of Virginia. ${ }^{28}$ SFQ rated over a scale of 0 (no problem) to 3 (severe problem) according to how patients had been feeling, and the participants were considered as poor for social functioning if they scored $\geq 10$ on SFQ. ${ }^{29}$ Using six semistructured questions that were adopted from a study done in India, attitude was considered as favorable $(\geq 18)$ using a mean score of 18 as a cutoff point. ${ }^{30}$ 
The coded data were entered into Epi Info software Version 3.5.3 and exported to SPSS Version 20 (IBM Corporation, Armonk, NY, USA) for analysis. Descriptive statistics were used to describe the data. Bivariate and multivariate logistic regression analyses were used to ascertain the association between covariates and the dependent variable. Odds ratios along with $95 \%$ CIs were used to show the strength of associations, and $P$-value $<0.05$ was considered as statistically significant.

\section{Results}

\section{Sociodemographic characteristics}

A total of 441 respondents participated in the study, giving a response rate of $97.1 \%$. Out of the 441 study participants, $221(50.1 \%)$ were females and 249 (56.5\%) were between the age group of 18 years and 30 years with the median age of 30 years with an interquartile range of 15 . Of the total participants, 311 (70.5\%) were Muslims, 413 (93.7\%) were Amhara in ethnicity, and 193 (43.8\%) were single. Among all study participants, 225 (51\%) were jobless, 281 (63.7\%) were urban residents, $116(26.3 \%)$ were in the second group of wealth score, and 347 (78.7\%) were living at a distance of $\leq 50 \mathrm{~km}$ away from the psychiatric clinic (Table 1).

\section{Clinical and patient-related factors}

Concerning clinical characteristics of the respondents, 234 (53.1\%) had schizophrenia; approximately one-third, 128 $(29 \%)$, had the diagnosis of depression; and the remaining had bipolar and anxiety disorders. Above half of the respondents, 260 (59\%), had duration of illness between 1 year and 5 years, and 235 (53.3\%) of the respondents had been taking more than one medication. Only 39 (8.8\%) of the respondents had comorbid physical illness. Poor social functioning was experienced by $52.4 \%$ of the respondents in the overall social functioning score.

\section{Satisfaction of psychiatric service consumers}

The overall satisfaction of respondents was $61.2 \%$ to the psychiatric service delivered at the Outpatient Department of Dessie Referral Hospital. Across all the 13 items measuring the patient satisfaction, almost half of the participants showed high satisfaction with the psychiatric services. The three items for which most patients showed higher satisfaction were monthly service bill (93.4\%), appearance of the office $(85.5 \%)$, and distance from transportation (84.4\%). The three items for which most patients showed lower satisfaction were amount of waiting time (49.4\%), location of
Table I Distribution of patients by sociodemographic factors at the psychiatric clinic of Dessie Referral Hospital in 2015 ( $N=44 I)$

\begin{tabular}{|c|c|c|}
\hline Variables & Frequency & Percent \\
\hline \multicolumn{3}{|l|}{ Age, years } \\
\hline $18-30$ & 249 & 56.5 \\
\hline $31-40$ & 104 & 23.6 \\
\hline $4 I-50$ & 52 & 11.8 \\
\hline$\geq 51$ & 36 & 8.2 \\
\hline \multicolumn{3}{|l|}{ Sex } \\
\hline Male & 220 & 49.9 \\
\hline Female & 221 & 50.1 \\
\hline \multicolumn{3}{|l|}{ Religion } \\
\hline Muslim & 311 & 70.5 \\
\hline Orthodox & 100 & 22.7 \\
\hline Protestant & 19 & 4.3 \\
\hline Catholic & 11 & 2.5 \\
\hline \multicolumn{3}{|l|}{ Marital status } \\
\hline Single & 193 & 43.8 \\
\hline Widowed & 35 & 7.9 \\
\hline Divorced & 44 & 10.0 \\
\hline Married & 169 & 38.3 \\
\hline \multicolumn{3}{|l|}{ Ethnicity } \\
\hline Amhara & 413 & 93.7 \\
\hline Others $* *$ & 28 & 6.3 \\
\hline \multicolumn{3}{|l|}{ Educational status } \\
\hline Not educated & 119 & 27.0 \\
\hline Primary & 127 & 28.8 \\
\hline Secondary & 123 & 27.9 \\
\hline Diploma and above & 72 & 16.3 \\
\hline \multicolumn{3}{|l|}{ Occupation } \\
\hline Jobless & 225 & 51.0 \\
\hline Had job & 216 & 49.0 \\
\hline \multicolumn{3}{|l|}{ Wealth index } \\
\hline Lowest & 81 & 18.4 \\
\hline Second & 116 & 26.3 \\
\hline Medium & 70 & 15.9 \\
\hline Fourth & 87 & 19.7 \\
\hline Highest & 87 & 19.7 \\
\hline \multicolumn{3}{|l|}{ Residence } \\
\hline Urban & 281 & 63.7 \\
\hline Rural & 160 & 36.3 \\
\hline \multicolumn{3}{|l|}{ Distance of the hospital } \\
\hline$\leq 50 \mathrm{~km}$ & 347 & 78.7 \\
\hline$>50 \mathrm{~km}$ & 94 & 21.3 \\
\hline
\end{tabular}

Note: **Others include Tigre, Affar, and Oromo.

the outpatient service (46\%), and appearance of the waiting area $(67.3 \%$; Table 2$)$.

\section{Factors associated with satisfaction of outpatient psychiatric service}

During the multivariate analysis of psychiatric outpatient service satisfaction in relation to all explanatory variables, sex, marital status, residence, type of mental illness, attitude toward the outpatient psychiatric clinic, and social functioning were found to be significantly associated. 
Table 2 Distribution of patients' satisfaction by each question at the psychiatric clinic of Dessie Referral Hospital in 20 I 5 ( $N=44$ I)

\begin{tabular}{lll}
\hline CPOSS items & Low satisfaction, $\mathbf{n}(\%)$ & High satisfaction, $\mathbf{n}(\%)$ \\
\hline Helpfulness of the professionals & $82(18.6)$ & $359(81.4)$ \\
Information provided about payment for services & $186(42.2)$ & $255(57.8)$ \\
Amount of time waiting to be seen & $218(49.4)$ & $223(50.6)$ \\
Amount of information given to you about your problem & $170(38.5)$ & $271(61.5)$ \\
Respect shown for your opinions about treatment & $130(29.5)$ & $311(70.5)$ \\
Matching of treatment plan to your individual needs & $123(27.9)$ & $318(72.1)$ \\
Helpfulness of the services you have received & $131(29.7)$ & $310(70.3)$ \\
Overall quality of care provided & $112(25.4)$ & $329(74.6)$ \\
Appearance of the waiting area & $297(67.3)$ & $144(32.7)$ \\
Appearance of the office & $64(14.5)$ & $377(85.5)$ \\
Office hours & $172(39.0)$ & $269(61.0)$ \\
Location of the outpatient service & $203(46)$ & $238(54)$ \\
Parking/distance of the clinic from public transportation & $69(15.6)$ & $372(84.4)$ \\
Clear and correct monthly bill & $29(6.6)$ & $412(93.4)$ \\
Would you recommend this program to a friend or family member? & $17(6.1)$ & $414(93.9)$
\end{tabular}

Abbreviation: CPOSS, Charleston Psychiatric Outpatient Satisfaction.

Male respondents treated at the outpatient psychiatric clinic were associated with less satisfaction as compared to females (adjusted odds ratio $[\mathrm{AOR}]=0.61,95 \%$ CI: $0.39,0.94)$. Patients who were widowed were less likely to be satisfied with the outpatient psychiatric service than those who were married $(\mathrm{AOR}=0.13,95 \% \mathrm{CI}$ : $0.05,0.36]$. Participants dwelling in the urban residence were less likely to be satisfied with the psychiatric service than their counterparts ( $\mathrm{AOR}=0.49,95 \% \mathrm{CI}: 0.31,0.78$ ). Respondents with a diagnosis of schizophrenia were less likely to be satisfied as compared to major depressive ones (AOR $=0.48,95 \%$ CI: $0.28,0.81$ ). Concerning the patient attitude toward the outpatient psychiatric service, those who had unfavorable attitude (AOR $=0.49,95 \% \mathrm{CI}$ : 0.28 , 0.86 ) were less likely to be satisfied as compared to those who had favorable attitude. Other significant association was found between social functioning of patients and satisfaction where those participants who had poor social functioning were less likely to be satisfied than those who had good social functioning (AOR $=0.52,95 \%$ CI: 0.34 , 0.80 ). On the other hand, education, distance from the health service facility, and wealth index had no statically significant association with outpatient psychiatric service satisfaction (Table 3).

\section{Discussion}

The overall prevalence of satisfaction in this study was $61.2 \%$ with $95 \%$ CI: $56.72-65.68$, and $93.3 \%$ of the respondents in this study said that they will recommend the service to a friend or other person in need of a similar service. The magnitude of satisfaction in this survey was consistent with the study done in India, which was $57 \%{ }^{9}$

The prevalence found in this study was found to be slightly higher than those of the studies done in London, ${ }^{7}$ USA and Canada, ${ }^{8}$ and Qatar, ${ }^{31}$ which reported prevalence rates of $39.3 \%, 44.8 \%$, and $49 \%$, respectively. However, the magnitude of satisfaction in this study was lower than that in three cross-sectional studies done in Nigeria (83\%), Durban (91.9\%), and Ireland (90.7\%)..$^{10,11,32}$ This finding was also lower than the finding from the follow-up study done in Sweden (77\%), ${ }^{33}$ comparative cross-sectional study done in Copenhagen $(80.4 \%),{ }^{7}$ and the study done in Pakistan $(90.7 \%){ }^{34}$

Age, educational status, employment, and expectation were not significantly associated with satisfaction as in other previous studies in Pakistan (younger age), ${ }^{34}$ USA and Canada (lower education), ${ }^{8}$ London and South Verona (paid employment), ${ }^{35}$ and five European countries (unmet needs). ${ }^{7}$ Males were 0.61 times less likely to be satisfied with psychiatric outpatient service as compared to females. The possible reason may be males show poor adherence to treatment and higher use of psychoactive substance that make them less responsive to psychiatric treatment. This idea coincides with the study done in Zurich ${ }^{36}$ and Geneva. ${ }^{37}$ Widowed respondents were 0.13 times less likely to be satisfied with psychiatric services as compared to those who were married. This might be explained by the fact that those who are widowed are more likely to be prone to psychological distress and adjustment difficulties, which in turn might affect the satisfaction. This finding agrees with the studies done in Geneva, ${ }^{37}$ London, and South Verona. ${ }^{35}$ 
Table 3 Factors associated with outpatient psychiatric service satisfaction at the Dessie Referral Hospital, Ethiopia, in 2015 ( $N=44 \mathrm{I})$

\begin{tabular}{|c|c|c|c|c|}
\hline \multirow{2}{*}{$\begin{array}{l}\text { Explanatory } \\
\text { variables }\end{array}$} & \multicolumn{2}{|c|}{ Satisfaction } & \multirow[t]{2}{*}{ COR $(95 \% \mathrm{Cl})$} & \multirow[t]{2}{*}{ AOR $(95 \% \mathrm{Cl})$} \\
\hline & Low & High & & \\
\hline \multicolumn{5}{|l|}{ Sex } \\
\hline Male & 92 & 128 & $0.77(0.52-1.13)$ & $0.61(0.39-0.94)^{*}$ \\
\hline Female & 79 & 142 & 1 & 1 \\
\hline \multicolumn{5}{|l|}{ Marital status } \\
\hline Single & 69 & 124 & $0.89(0.57-1.37)$ & $1.37(0.84-2.24)$ \\
\hline Widowed & 29 & 6 & $0.10(0.04-0.26)$ & $0.13(0.05-0.36)^{* *}$ \\
\hline Divorced & 17 & 27 & $0.78(0.39-1.56)$ & $0.87(0.4 I-I .84)$ \\
\hline Married & 56 & 113 & 1 & 1 \\
\hline \multicolumn{5}{|l|}{ Educational status } \\
\hline Primary & 48 & 79 & I & 1 \\
\hline Secondary & 44 & 79 & $1.09(0.65-1.82)$ & $1.06(0.59-1.89)$ \\
\hline Not educated & 43 & 76 & $1.07(0.64-1.80)$ & $1.28(0.69-2.38)$ \\
\hline$\geq$ Diploma & 36 & 36 & $0.60(0.33-1.09)$ & $0.65(0.33-1.26)$ \\
\hline \multicolumn{5}{|l|}{ Wealth index } \\
\hline Lowest & 31 & 50 & I & 1 \\
\hline Second & 42 & 74 & $1.09(0.60-1.96)$ & $0.84(0.43-1.63)$ \\
\hline Medium & 32 & 38 & $0.73(0.38-I .4 I)$ & $0.69(0.33-1.44)$ \\
\hline Fourth & 34 & 53 & $0.96(0.5 I-1.79)$ & $0.79(0.39-1.58)$ \\
\hline Highest & 32 & 55 & $1.06(0.57-1.99)$ & $0.97(0.48-1.95)$ \\
\hline \multicolumn{5}{|l|}{ Residence } \\
\hline Urban & 120 & 161 & $0.62(0.4 I-0.94)$ & $0.49(0.3 \mathrm{I}-0.78)^{* * *}$ \\
\hline Rural & 51 & 109 & 1 & 1 \\
\hline \multicolumn{5}{|l|}{ Distance $(\mathrm{km})$} \\
\hline$\leq 50$ & 143 & 204 & 1 & I \\
\hline$>50$ & 28 & 66 & $1.65(1.01-2.70)$ & $1.64(0.95-2.83)$ \\
\hline \multicolumn{5}{|c|}{ Type of mental illness } \\
\hline MDD & 39 & 89 & 1 & 1 \\
\hline Psychosis & 100 & 134 & $1.66(0.62-4.44)$ & $0.48(0.28-0.8 \mathrm{I})^{* * * *}$ \\
\hline Bipolar & 24 & 36 & $0.97(0.37-2.5 \mathrm{I})$ & $0.56(0.28-1.11)$ \\
\hline Anxiety & 8 & 11 & $1.09(0.38-3.10)$ & $0.79(0.26-2.38)$ \\
\hline \multicolumn{5}{|l|}{ Attitude } \\
\hline Unfavorable & 39 & 38 & $1.80(1.09-2.96)$ & $0.49(0.28-0.86)^{*}$ \\
\hline Favorable & 132 & 232 & 1 & 1 \\
\hline \multicolumn{5}{|l|}{ Social functioning } \\
\hline Poor & 110 & 121 & $2.22(1.49-3.29)$ & $0.52(0.34-0.80)^{* * *}$ \\
\hline Good & 61 & 149 & $\mathrm{I}$ & 1 \\
\hline
\end{tabular}

Notes: $* P$-value $<0.05, * * P$-value $<0.00 \mathrm{I}$, and $* * * P$-value $<0.0 \mathrm{I}$. I= reference for category.

Abbreviations: $\mathrm{COR}$, crude odds ratio; $\mathrm{Cl}$, confidence interval; $\mathrm{AOR}$, adjusted odds ratio; MDD, major depressive disorder.

Respondents from urban residence were 0.49 times less likely to be satisfied with mental health service as compared to those from rural residence. There was no significant association in previous studies for residence. A possible explanation for this study seems to be that satisfaction of patients is dependent on their personal beliefs and expectations about the service. Patients from urban residence come with more expectation from the service as a result of alternative service experience, improved living style, increasing information access about medical service, and higher education, while this is not true for the rural ones. The finding of this study showed that schizophrenic patients were 0.48 times less likely to be satisfied with mental health service as compared to patients with major depressive disorder. This is similar to studies done in India, ${ }^{9}$ Canada and USA, ${ }^{8}$ and Switzerland. ${ }^{36}$

The odds of participants with unfavorable attitude were 0.49 times less likely to be satisfied with mental health service as compared to those with favorable attitude. The possible reason might be that unfavorable attitude toward the service will create a negative environment in doctor-patient relationship that can decrease compliance and trust of treatment and increase dropout from follow-up. This coincides with the study done in India. ${ }^{30}$ Regarding social functioning, respondents with poor social functioning were $0.52 \%$ times less likely to be satisfied with mental health service than those with good social functioning, and it was supported by the study done in Sweden. ${ }^{33}$

\section{Conclusion}

In this study, the satisfaction level of patients was found to be low. Being male, widowed, diagnosed with schizophrenia, urban residence, unfavorable attitude, and poor social functioning were found to have a statistically significant association with satisfaction. Integrating patients to their own treatment plan and regular service evaluation are important to improve satisfaction. Moreover, working on the attitudes of psychiatric service consumers may increase the level of patient satisfaction. It will be helpful if researchers try to investigate the area by including other important factors such as severity of the illness.

\section{Acknowledgments}

The authors like to acknowledge the study participants for their precious time and genuine cooperation, Amanuel Mental Specialized Hospital for financial and material support, and management and psychiatric clinic staff members of Dessie Referral Hospital for their support and positive cooperation.

\section{Author contributions}

All authors had equal substantial contributions to conception and design, acquisition of data, analysis and interpretation of data, and drafting and revising of the article. All authors read and approved the final manuscript and agreed to be accountable for all aspects of the work.

\section{Disclosure}

The authors report no conflicts of interest in this work. 


\section{References}

1. Gill L, White L. A critical review of patient satisfaction. Leadersh Health Serv. 2009;22(1):8-19.

2. Bleich SN, Ozaltin E, Murray CK. How does satisfaction with the health-care system relate to patient experience? Bull World Health Organ. 2009;87(4):271-278.

3. Blenkiron $P$, Hammill CA. What determines patients' satisfaction with their mental health care and quality of life? Postgrad Med J. 2003; 79(932):337-340.

4. Bramesfeld AWF, Elgeti H, Bisson S. How does mental health care perform in respect to service user's expectations? Evaluating inpatient and outpatient care in Germany with the WHO responsiveness concept. BMC Health Serv Res. 2007;7(99):1-12.

5. Leonard KL. Is patient satisfaction sensitive to changes in the quality of care? An exploitation of the Hawthorne effect. J Health Econ. 2008; 27(2):444-459.

6. Boyer L, Lançon C, Baumstarck K, Parola N, Berbis J, Auquier P. Evaluating the impact of a quality of life assessment with feedback to clinicians in patients with schizophrenia: randomised controlled trial. Br J Psychiatry. 2013;202(6):447-453.

7. Ruggeri M, Lasalvia A, Bisoffi G, et al; EPSILON Study Group. Satisfaction with mental health services in five European sites: results from the EPSILON study. Schizophr Bull. 2003;29(2):229-245.

8. Stein MB, Roy-Byrne PP, Craske MG, et al. Quality of and patient satisfaction with primary health care for anxiety disorders. $J$ Clin Psychiatry. 2011;72(7):970-976.

9. Holikatti PC, Kar N, Mishra A, Shukla R, Swain SP, Kar S. A study on patient satisfaction with psychiatric services. Indian J Psychiatry. 2012;54(4):327-332.

10. Lally J, Byrne F, McGuire E, McDonald C. Patient satisfaction with psychiatric outpatient care in a university hospital setting. Ir J Psychol Med. 2013;30(04):271-277.

11. Almeida R, Adejumo O. Consumer satisfaction with community mental health care in Durban: research. Health SA Gesondheid. 2004; 9(1):3-9.

12. Osborn DPJ, Lloyd-Evans B, Johnson S, et al. Residential alternatives to acute in-patient care in England: satisfaction, ward atmosphere and service user experiences. Br J Psychiatry Suppl. 2010;197(suppl 53): $\mathrm{s} 41-\mathrm{s} 45$.

13. Abdosh B. The quality of hospital services in eastern Ethiopia: patient's perspective. Ethiop J Health Dev. 2006;20(3):199-200.

14. Dagnew M, Zakus D. Community perception on OPD performance of a teaching hospital in Gondar town. Ethiop Med J. 1997;35(3):153-160.

15. Wright SM, Craig T, Campbell S, Schaefer J, Humble C. Patient satisfaction of female and male users of veterans health administration services. J Gen Intern Med. 2006;21(suppl 3):S26-S32.

16. Quintana JM, González N, Bilbao A, et al. Predictors of patient satisfaction with hospital health care. BMC Health Serv Res. 2006;6(102): $1-9$.

17. Garland AF, Aarons GA, Saltzman MD, Kruse MI. Correlates of adolescents' satisfaction with mental health services. Ment Health Serv Res. 2000;2(3):127-139.

18. Mattsson M, Lawoko S, Cullberg J, Olsson U, Hansson L, Forsell Y. Background factors as determinants of satisfaction with care among first-episode psychosis patients. Soc Psychiatry Psychiatr Epidemiol. 2005;40(9):749-754.
19. Zendjidjian XY, Auquier P, Lançon C, et al. Determinants of patient satisfaction with hospital health care in psychiatry: results based on the S ATIS PSY-22 questionnaire. Patient Prefer Adherence. 2014;8: 1457-1464.

20. Jackson JL, Chamberlin J, Kroenke K. Predictors of patient satisfaction. Soc Sci Med. 2001;52(4):609-620.

21. Bruckner TA, Scheffler RM, Shen G, et al. The mental health workforce gap in low- and middle-income countries: a needs-based approach. Bull World Health Organ. 2011;89(3):184-194.

22. Kruk ME, Freedman LP. Assessing health system performance in developing countries: a review of Literature. Health Policy. 2008;85(3): 263-276.

23. Powell RA, Single HM, Lloyd KR. Focus groups in mental health research: enhancing the validity of user and provider questionnaires. Int J Soc Psychiatry. 1996;42(3):193-206.

24. Ahmad I, Din SU. Patients satisfaction from the health care services. Gomal J Med Sci. 2010;8(1):95-97.

25. Pellegrin KL, Stuart GW, Maree B, Frueh BC, Ballenger JC. A brief scale for assessing patients' satisfaction with care in outpatient psychiatric services. Psychiatr Serv. 2001;52(6):816-819.

26. Salam AA, Alshekteria AA, Alhadi HA, Ahmed M, Mohammed A. Patient satisfaction with quality of primary health care in Benghazi, Libya. Libyan J Med. 2010;5(1).

27. Ukpong DI, Mosaku SK, Aloba O, Mapayi B. Reliability and validity of a satisfaction scale in a Nigerian psychiatric out-patient clinic. Niger J Psychiatry. 2008;6(1):31-36.

28. Oltmanns TF, Melley AH, Turkheimer E. Impaired social function and symptoms of personality disorders assessed by peer and self-report in a nonclinical population. J Pers Disord. 2002;16(5):437-452.

29. Remington M, Tyrer P. The social functioning schedule - a brief semistructured interview. Soc Psychiatry. 1979;14:151-157.

30. Ibrahim A, Chompikul J, Isaranurug S. Patient satisfaction with health services at the outpatient department of Indira Gandhi memorial Hospital, Male'Maldives. J Public Health Dev. 2008;6(1):144-152.

31. Ghuloum S, Bener A, Burgut FT. Ethnic differences in satisfaction with mental health services among psychiatry patients. Open Psychiatry J. 2010;4:19-24.

32. Bener A, Ghuloum S. Gender difference on patients' satisfaction and expectation towards mental health care. Niger J Clin Pract. 2013;16(3): 285-291.

33. Clinton D, Björck C, Sohlberg S, Norring C. Patient satisfaction with treatment in eating disorders: cause for complacency or concern? Eur Eat Disord Rev. 2004;12(4):240-246.

34. Gani N, Saeed K, Minhas FA, Anjuman N, Waleed M, Fatima G. Assessment of patient satisfaction with mental health services in a tertiary care setting. J Ayub Med Coll Abbottabad. 2011;23(1):43-46.

35. Henderson C, Phelan M, Loftus L, Dall'Agnola R, Ruggeri M. Comparison of patient satisfaction with community-based vs. hospital psychiatric services. Acta Psychiatr Scand. 1999;99(3):188-195.

36. Hasler G, Moergeli H, Bachmann R, Lambreva E, Buddeberg C, Schnyder U. Patient satisfaction with outpatient psychiatric treatment: the role of diagnosis, pharmacotherapy, and perceived therapeutic change. Can J Psychiatry. 2004;49(5):315-321.

37. Davy B, Keizer I, Croquette P, et al. Patient satisfaction with psychiatric outpatient care in Geneva: a survey in different treatment settings. Schweizer Archiv Fuer Neurologie Und Psychiatrie. 2009;160(6):240.
Patient Preference and Adherence

\section{Publish your work in this journal}

Patient Preference and Adherence is an international, peer-reviewed, open access journal that focuses on the growing importance of patient preference and adherence throughout the therapeutic continuum. Patient satisfaction, acceptability, quality of life, compliance, persistence and their role in developing new therapeutic modalities and compounds to optimize

\section{Dovepress}

clinical outcomes for existing disease states are major areas of interest for the journal. This journal has been accepted for indexing on PubMed Central. The manuscript management system is completely online and includes a very quick and fair peer-review system, which is all easy to use. Visit http://www. dovepress.com/testimonials.php to read real quotes from published authors. 